\title{
Bang-Bang Control Technique Based Lab Scaled Steam Turbine-Generator Set Test Bench
}

\author{
Engr. Mohammad Faisal Haider ${ }^{1}$, and Engr. Sajjad Mehmood ${ }^{2}$
}

\begin{abstract}
Due to the increased generation of electricity from coal, oil and other fossil fuels, energy and environmental issues have become the major concerns around the globe. Thus this paper has been initiated to develop a steam generator based multitasking test bed that have analyzed the relationship of key parameters of the steam turbine-generator set such as pressure, temperature and turbine's rpm, with the variation of load. The bang-bang based control algorithm has been applied to control the rpm of the steam turbine-generator set according to the load requirements. At the end of the thesis, performance analysis has been carried out in MATLAB/Simulink on different scenarios with respect to load.
\end{abstract}

Keywords - Open-Loop Control Systems, Closed-Loop Control Systems

\section{INTRODUCTION}

$\mathrm{T}$ HE world is facing very serious energy threats because of the increasing consumption of electricity and global warming. One of the reasons behind the problem is the vigorous exploitation of fossil fuel reserves of the world in the last century. So as to compete with energy challenges, scientists and engineers are working day and night for the well being of our community. Now scientists prefer those sources of energy that are renewable and environmental friendly as well. So paradigm shift is being observed as far as prime mover of electricity is being concerned $[1,2]$.

Out of the many sources of renewable energy such as water, wind, and solar, steam energy is still considered popular source of electricity production globally because of less cost [3].

\section{CONTROL TECHNIQUES}

A control system by definition consists of the system to be controlled - called the plant, as well as the system which exercise control over the plant, called the controller [4]. A controller could be either human being, or an artificial device. The controller is said to apply the signal to the plant called the input to the plant (or control input), in order to produce the desired response from the plant, called the output from the

Faisal Haider ${ }^{1}$ is with the Superior Group of Colleges, University Campus, Lahore, Pakistan.

Sajjad Mehmood ${ }^{2}$ is with Superior Group of Colleges, University Campus, Lahore, Pakistan. plant. The relationship between the input and output of the system are further divided into two categories:

i) Open-Loop Control Systems

ii) Closed-Loop Control Systems

Such a control system, in which the control input is applied without the knowledge of the plant output, is called an openloop control system. The Figure 1 shows the block diagram of an open-loop control system.

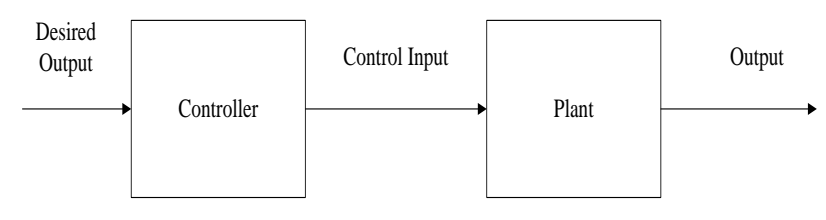

Fig. 1 Open-Loop Control Systems [5]

A control system in which the control input is a function of the plant's output is called a Closed-Loop control system. Since in a Closed-Loop system, the controller is constantly in touch with the actual output, it is likely to succeed in achieving the desired output even in the presence of noise or uncertainty in the linear plant behavior. The mechanism by which the information about the actual output is communicated to the controller is called a feedback. In Figure 2, the path from the plant output to the controller input is called a feedback-loop $[5,6]$.

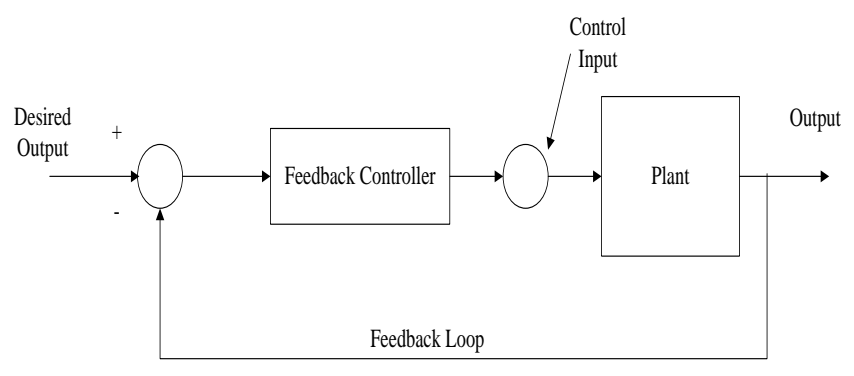

Fig. 2 Closed-Loop Control System [5]

The input applied to the controller is called the error signal. It represents the difference between the set point signal and the feedback signal. The error signal is expressed by the following formula:

Error Signal e $(\mathrm{t})=$ Set Point - Feedback Signal 


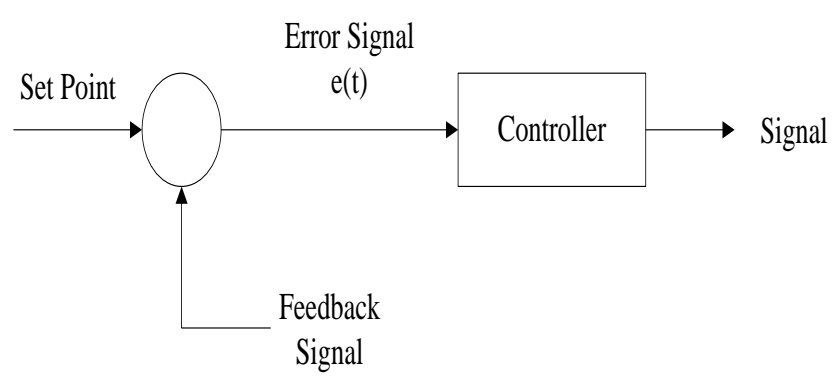

Fig. 3 A Feedback Control System [7]

The Bang-Bang control mode is the most basic type of control system. Its output has only two states, usually fully 'On' and fully 'Off'. One state is used when the controlled variable (e.g., temperature, pressure, rpm, voltage) is above the desired value (set point). The other state is used when the controlled variable is below the set point. The bang-bang controller is also referred to as the two-position, or On-Off control [7].

In control theory, a Bang-Bang controller is a feedback controller that switches suddenly between two states. These controllers may be realized in terms of any part that provides hysteresis. They are implemented where the plant acknowledges signals in the form of 1's \& 0's (binary signal), for example a boiler that is either entirely 'On' or completely 'Off' [8].

Thus Bang-Bang controllers controls are actually optimal controls in some cases, although they are also often implemented because of ease or convenience. Figure 4 illustrates the Bang-Bang controller.

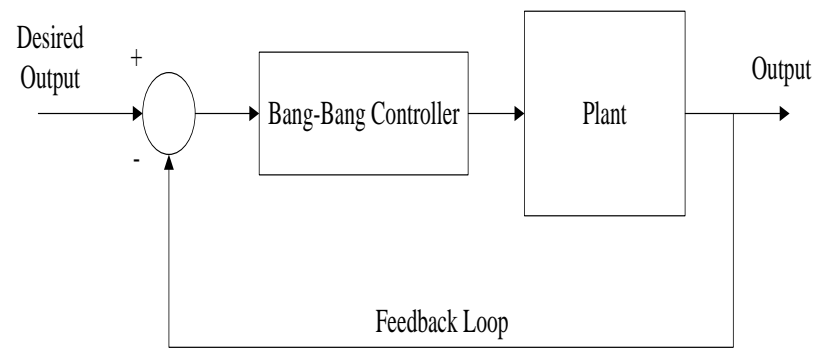

Fig. 4 A Bang-Bang Controller

\section{SYSTEM MODEL}

The system constitutes two major parts. The first part is responsible for the power generation i.e. steam turbinegenerator set and the other is monitoring and control of different system parameter such as generated voltage, load current, load power, turbine's RPMs and steam temperature i.e. microcontroller based design.

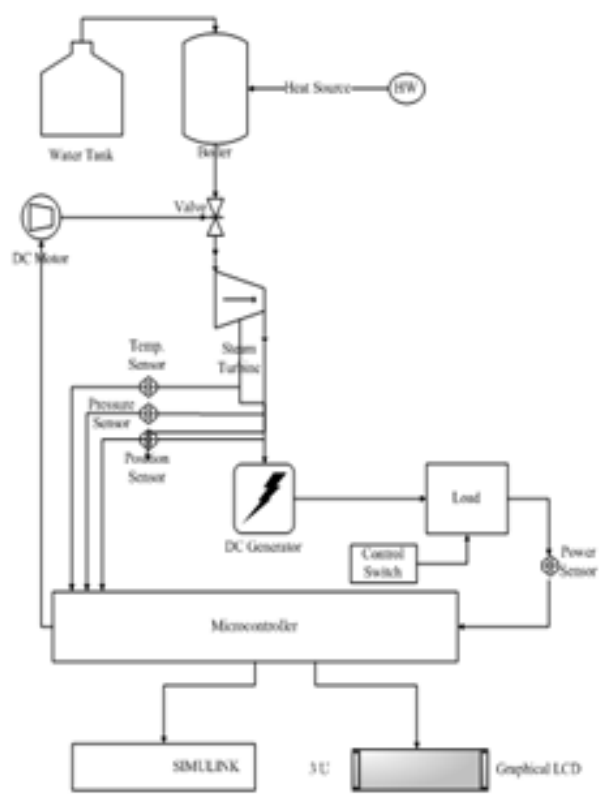

Fig. 5 Block Diagram of the Test Bed

\section{MicROCONTROLLER BASED DESIGN}

The microcontroller is playing a major role in an emerging field of Electrical engineering. Many technical processes and products in the area of Electrical engineering show an increasing integration of sensors and actuators with the microcontrollers [9].

In this project, various sensors have been interfaced with the microcontroller, for instance temperature sensor to measure temperature of steam, position sensor for measuring RPMs of the steam turbine. Interfacing of shunt resistance and voltage dividers are being done to measure current and voltages respectively. Table 1 shows their details.

The maximum power utilization of the system is also measured by the microcontroller. Bang-Bang based control logic is executed by the microcontroller as to control the rotation of the outlet valve of the boiler which in turn regulate the RPMs of the steam turbine as per the load requirements. Graphical LCD has been interfaced to view the values of the above mentioned parameters. Serial data is also being transmitted to the PC as to monitor it on the GUI/Simulink via RS232 protocol.

TABLE I

COMPONENT INTERFACING DETAILS

\begin{tabular}{|l|l|l|}
\hline Sr. No. & Part Name & Purpose \\
\hline 1 & Posí̄on Sensor (LM12-3004PA) & Turbine Speed (RPMs) \\
\hline 2 & Shunt Resistor & Load Current \\
\hline 3 & Voltage Divider & Load Voltage \\
\hline 4 & Temperature Sensor (AD595CQ) & Temperature Measurements \\
\hline
\end{tabular}

PIC18F452 have been chosen because it meets the task at hand efficiently and cost effectively. Its speed, packaging, power consumption, amount of RAM/ROM available, and number of I/O pins are well sufficient for the desire design. The key features for the PIC18F452 are given in Table 2. 
TABLE II

THE KeY FEATURES FOR THE PIC 18F452 [9]

\begin{tabular}{|l|l|l|l|l|l|l|l|}
\hline Part Num. & $\begin{array}{l}\text { Code } \\
\text { ROMI }\end{array}$ & $\begin{array}{l}\text { Data } \\
\text { RAM }\end{array}$ & $\begin{array}{l}\text { Data } \\
\text { EEPROMI }\end{array}$ & IO Pias & ADC & Timers & $\begin{array}{l}\text { Pin } \\
\text { Num. \& } \\
\text { Package }\end{array}$ \\
\hline PIC18F452 & $\begin{array}{l}32 \mathrm{~K} \\
\text { (flash) }\end{array}$ & 1536 & 256 & 36 & $\begin{array}{l}10- \\
\text { bit }\end{array}$ & 4 & 40 DIP \\
\hline
\end{tabular}

Real-time microcontroller based design for test bed is shown in Figure 6.

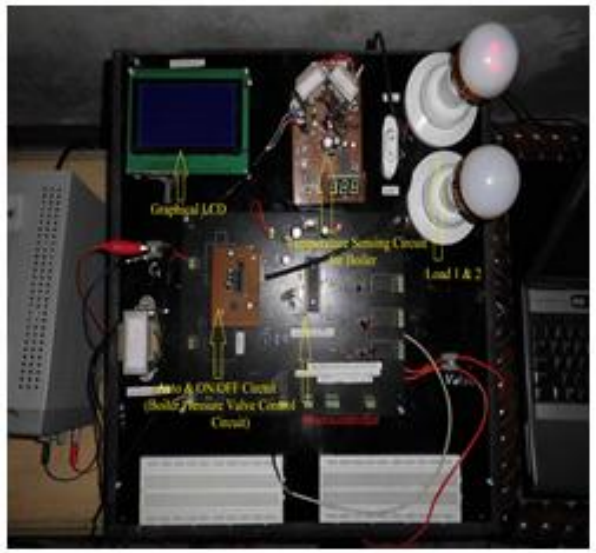

Fig. 6 Real-time Microcontroller Based Design for Test Bed

\section{SYSTEM MODEL EXECUTION}

The actual flow chart of the system is being discussed in this section.

\subsection{Flow Chart}

The flow chart given in Figure 7 describes the complete logic of the test bed being taken.

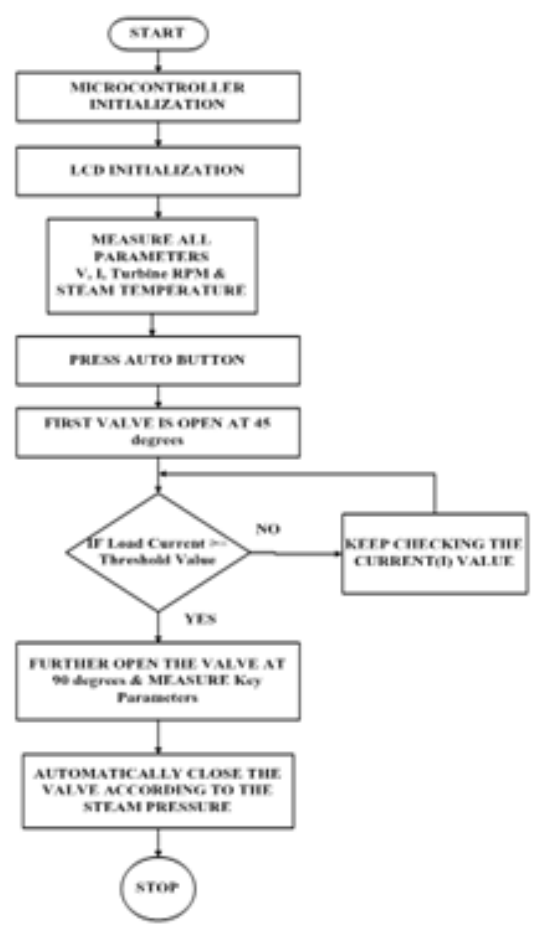

Fig. 7 Flow Chart of the System

\subsection{Schematic Diagram:}

Figure 8 has shown the schematic diagram for the microcontroller based design.

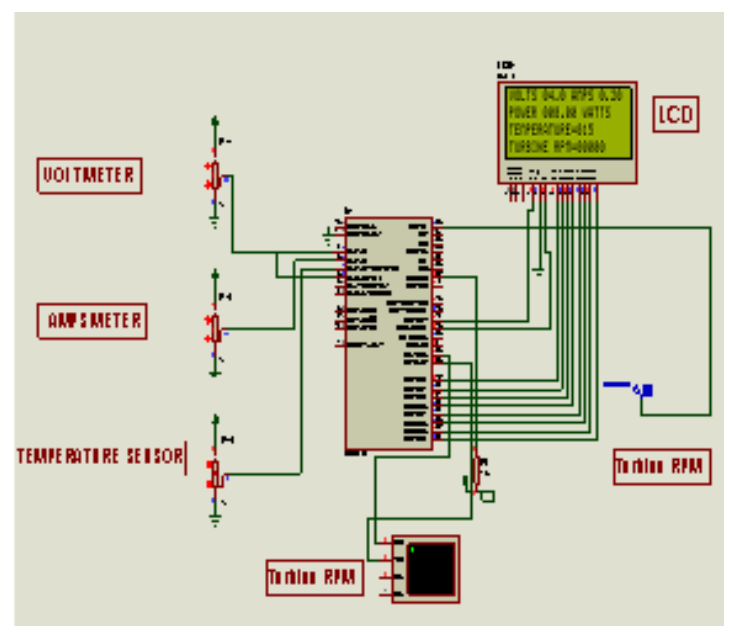

Fig. 8 The Schematic Diagram

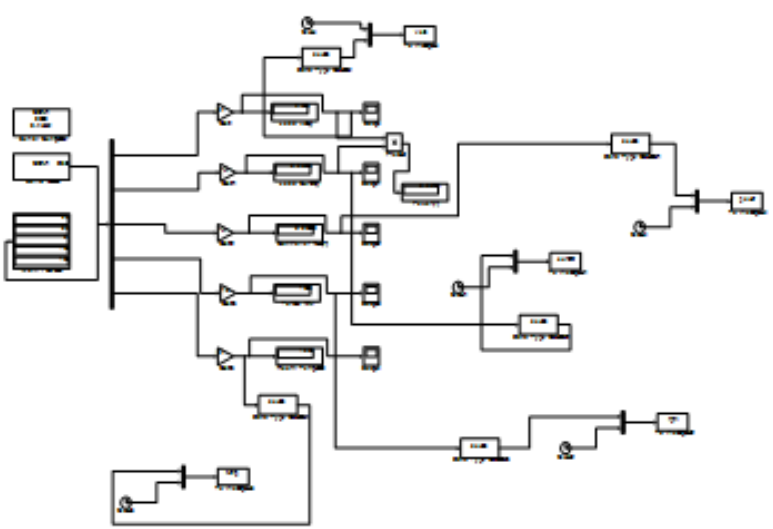

Fig. 9 Complete Simulink Model of the System in an Active State

The purpose of this experimentation work is to test the implemented control algorithm in which the turbine's RPMs are varied with respect to the load variations.

For verification, threshold of $90 \mathrm{~mA}$ has been set and as the current violates this threshold condition, control algorithm will be activated and send a control signal to further open the boiler's outlet valve, that will increase the steam pressure and eventually turbine RPM's will be compensated with respect to the requirements.

If the current reaches below threshold value, the outlet valve starts to close, steam pressure reduces and turbine RPM's decreases accordingly.

As shown in the Figure 9, a gear system has been placed to control position of the outlet valve. Three positions have been set, in terms of angle (degrees) at $0^{0}$ the valve is fully closed, at $45^{\circ}$ the valve is half opened while at $90^{\circ}$ the valve is fully opened and the maximum steam will be released from boiler. The description of these experiments is given below.

\subsection{Experiment No. 1: No Load Condition:}

In this experiment, the system has been tested under no load condition and results have been analyzed. 
As shown in the Figure 10 , at $\mathrm{t}=10 \mathrm{~s}$, the valve has been operated through push button. Turbine RPM's are stabilized at $\mathrm{t}=20 \mathrm{~s}$. At $\mathrm{t}=25 \mathrm{~s}$, the generator's peak voltage is recorded i.e. $7 \mathrm{~V}$.

During the experiment, load is not switched ON; hence the current and power values have remained zero. At $t=35 \mathrm{~s}$, the turbine's RPMs starts to decrease which reflects the gradual decrease in the generator voltage as well. In the end at $t=120 \mathrm{~s}$, the system reaches its initial position.
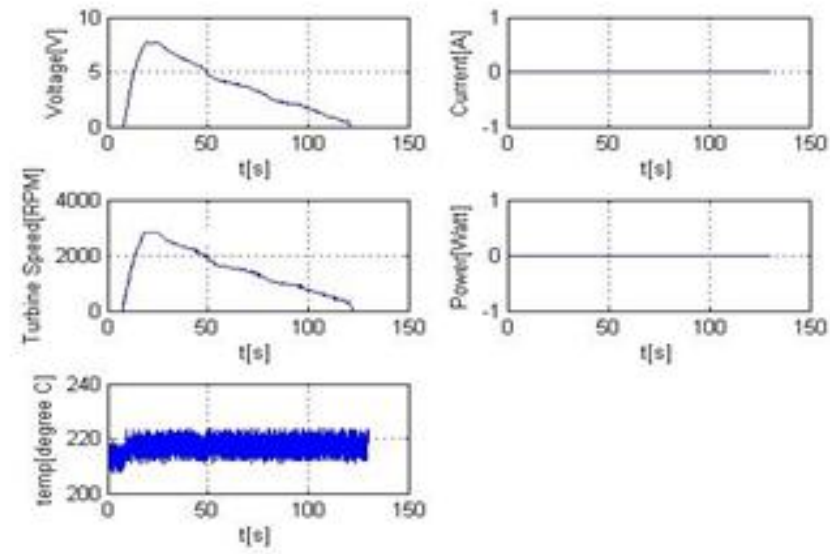

Fig. 10 Experiment No. 1 No Load Condition

TABLE III

RESULTS FOR EXPERIMENT NO. 1 NO LOAD CONDITION

\begin{tabular}{|c|c|c|c|c|c|c|}
\hline Timmory & Votary $(n)$ & Curretentions) & Powe(Tivent) & $\begin{array}{l}\text { Twabee } \\
\text { RPMNS }\end{array}$ & $\begin{array}{l}\text { Alg: } \\
\text { Tomperane } \\
\text { ("C) }\end{array}$ & 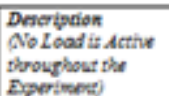 \\
\hline$?=0$ & 0 & 0 & 0 & 0 & 0 & strem is of \\
\hline$t=10$ & 5 & 0 & 0 & 0 & 215 & 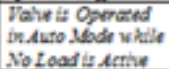 \\
\hline$\xi=20$ & 7 & 0 & 0 & 2200 & 215 & 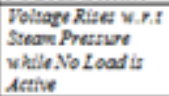 \\
\hline$?=30$ & 7 & 0 & 0 & 28000 & 2215 & 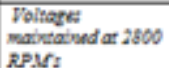 \\
\hline$y=40$ & 6 & 0 & 0 & 2000 & 2215 & 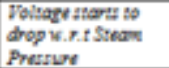 \\
\hline$g=60$ & 3 & 0 & 0 & 1800 & 2135 & Foltoge dropgeng \\
\hline$:=80$ & 4 & 0 & 0 & 1000 & 2115 & 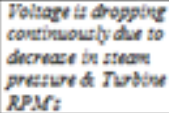 \\
\hline$t=100$ & 3 & 0 & 0 & 300 & 273 & 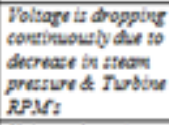 \\
\hline$t=120$ & 7 & 0 & 0 & 1000 & 275 & 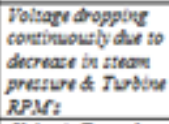 \\
\hline$t=140$ & 0 & 0 & 0 & 0 & 2125 & $\begin{array}{l}\text { Valve is Thomed } \\
\text { of }\end{array}$ \\
\hline$?=150$ & 0 & 0 & 0 & 0 & 0 & $\begin{array}{l}\text { Fersen is Tomed } \\
\text { or }\end{array}$ \\
\hline
\end{tabular}

\subsection{Experiment No. 2: Half Load Condition:}

In this experiment, the system runs under auto control mode in half load condition. The purpose of the experiment is to analyze the implemented control technique, i.e. Bang-Bang Control Technique, during the experiment only one bulb is remained ON. Figure 11 shows the plots taken in this experiment. At $\mathrm{t}=20 \mathrm{~s}$, results have been shown that as the current violates the threshold condition i.e. $I=90 \mathrm{~mA}$, the outlet valve is opened and eventually the increased steam pressure has affected the increase of turbine RPMs from 2700 to 3100 , which verifies the implementation of the Bang-Bang Control. At $\mathrm{t}=20 \mathrm{~s}$, as the threshold condition is violated and the outlet valve starts to open further from $45^{\circ}$ to $90^{\circ}$ to compensate the steam pressure accordingly to the requirement. After a certain time, the pressure reduces the turbine RPMs and in the end at $\mathrm{t}=110 \mathrm{~s}$ the bulb is turned off and the system becomes idle at $\mathrm{t}=120 \mathrm{~s}$. Table 6 shows the generated results.
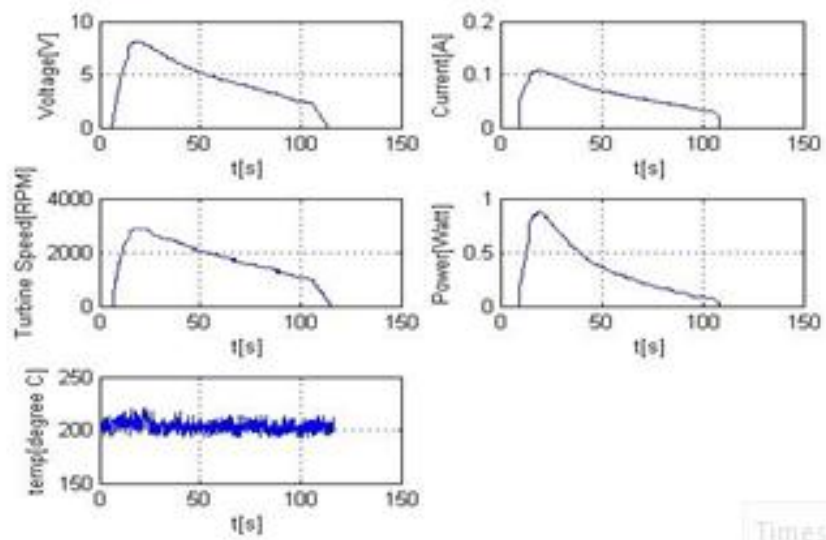

Fig. 11 Experiment No. 2 Half Load Condition

TABLE IV

RESULTS FOR EXPERIMENT NO. 2 HALF LOAD CONDITION

\begin{tabular}{|c|c|c|c|c|c|}
\hline Tone(s) & $\operatorname{Vot}(V)$ & Currentind & Power(Want) & $\begin{array}{l}\text { Temperature } \\
\left({ }^{\circ} \mathrm{C}\right)\end{array}$ & $\begin{array}{l}\text { Decription } \\
\text { (Halyoad is Aetive } \\
\text { throughout the } \\
\text { Experiment) }\end{array}$ \\
\hline$F=0$ & 0 & 0 & 0 & 0 & System E OH \\
\hline$t=10$ & 0 & 0 & 0 & 215 & $\begin{array}{l}\text { System is Tirned } \\
\text { On }\end{array}$ \\
\hline$t=M$ & 5 & 0 & 0 & 215 & Vahe E Operaned \\
\hline$f=15$ & 8 & 50 & 0.4 & 215 & $\begin{array}{l}\text { Fost Bublo } \\
\text { Twrned On }\end{array}$ \\
\hline$t=20$ & 7 & 100 & 0.7 & 215 & 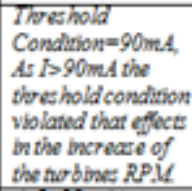 \\
\hline$t=30$ & 6.5 & 88 & 5.72 & 215 & 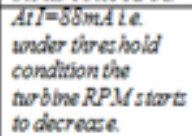 \\
\hline$F=40$ & 6 & 50 & 0.48 & 215 & $\begin{array}{l}\text { Volitagestart io } \\
\text { docreaze according } \\
\text { to stham pressure }\end{array}$ \\
\hline$t=50$ & 5.5 & 70 & 3.85 & 215 & $\begin{array}{l}\text { Volitage start to } \\
\text { docreace actording }\end{array}$ \\
\hline$t=65$ & 5 & 60 & 0.3 & 215 & 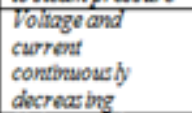 \\
\hline$f=100$ & 3 & 45 & 0.12 & 215 & $\begin{array}{l}\text { Voltage and } \\
\text { current } \\
\text { contbunous by } \\
\text { decreas big }\end{array}$ \\
\hline$t=110$ & 15 & 0 & 0 & 215 & Bub tarned off \\
\hline$F=120$ & 0 & 0 & 0 & 215 & Vaive Twhid OP \\
\hline
\end{tabular}

\subsection{Experiment No. 3: Full Load Condition:}

In this experiment the system runs under auto control mode in full load condition. The purpose of the experiment is to analyze the implemented control technique, i.e. Bang-Bang Control Technique. During the experiment, the two bulbs are operated one by one. Figure 12 shows the plots being taken in 
this experiment. At $\mathrm{t}=20 \mathrm{~s}$, results have shown that as the current violated the threshold i.e. $\mathrm{I}=90 \mathrm{~mA}$ to $200 \mathrm{~mA}$ (both bulbs are in ON state), the outlet valve is further opened and eventually steam pressure increases Turbine RPMs from 2700 to 3100 . At $\mathrm{t}=45 \mathrm{~s}$, I becomes $85 \mathrm{~mA}$ from $180 \mathrm{~mA}$ (one bulb is switch OFF). At this point once again a decrease in turbine's RPMs have been recorded i.e. 2400 to 1600 .At $t=20 \mathrm{~s}$, as the threshold condition is violated, the outlet valve starts to open further from $45^{\circ}$ to $90^{\circ}$. At $\mathrm{t}=45 \mathrm{~s}$, valve starts to close from $90^{\circ}$ to $45^{\circ}$, in order to decrease the steam pressure and eventually turbine RPM's as well. As the pressure reduces, the turbine RPMs are decreased and in the end at $t=110 \mathrm{~s}$, the bulb is turned $\mathrm{OFF}$ and the system reaches at $\mathrm{t}=120 \mathrm{~s}$. Table 7 shows the generated results.

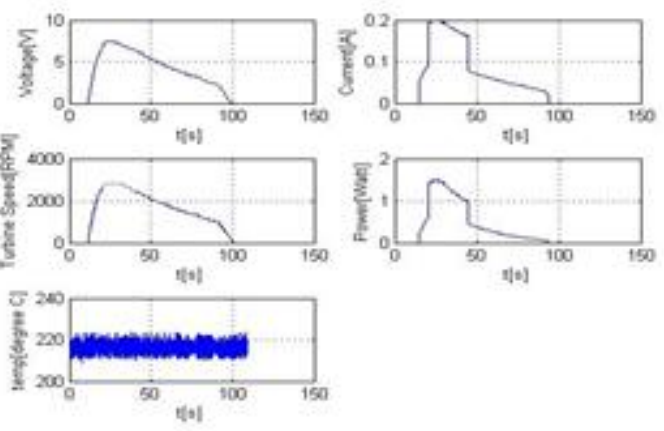

Fig. 12 Experiment No. 3 Full Load Condition

TABLE $\mathrm{V}$

RESULTS FOR EXPERIMENT NO. 3 FULL LOAD CONDITION

\begin{tabular}{|c|c|c|c|c|c|c|}
\hline TImenti & Votang & Cintertint) & Powe(Wats) & $\begin{array}{l}\text { TuFbs } \\
\text { RPM/s }\end{array}$ & $\begin{array}{l}\text { A's. } \\
\text { Touperare } \\
\left({ }^{\circ} \mathrm{C}\right)\end{array}$ & 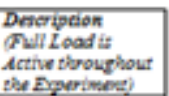 \\
\hline$f=0$ & 8 & 0 & 8 & 8 & 8 & Sytem is of \\
\hline$f=10$ & 0 & 0 & 0 & 0 & 213 & Satrem to Tomed \\
\hline$t=I I$ & 3 & 30 & 0.25 & 300 & 213 & $\begin{array}{l}\text { Fing bus is } \\
\text { Thimed on }\end{array}$ \\
\hline$F=13$ & 6 & 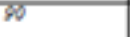 & 0.34 & 2700 & 213 & Treaches to \\
\hline$t=20$ & 7 & 200 & 0.8 & 3100 & 213 & 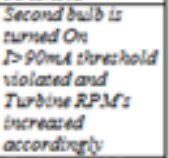 \\
\hline$t=16$ & 6.5 & 156 & 0.65 & 2400 & 213 & 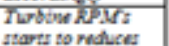 \\
\hline$t=45$ & 6 & 85 & 0.51 & 1600 & 213 & 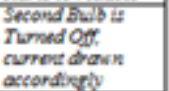 \\
\hline$=30$ & 3 & 65 & 0.3 & 1200 & 213 & 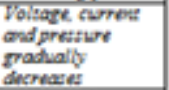 \\
\hline$f=50$ & 4 & 45 & 2.18 & 900 & 213 & 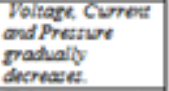 \\
\hline$=70$ & 3 & 33 & 009 & 400 & 213 & 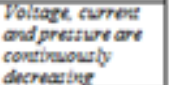 \\
\hline$t=0$ & 2 & 20 & 2.04 & 200 & 213 & 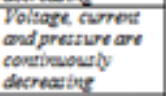 \\
\hline$\frac{f=90}{t=100}$ & & 0 & & $\frac{100}{6}$ & $\frac{213}{213}$ & DElb torved of \\
\hline
\end{tabular}

\section{HARDWARE}

Figure 13 shows the complete integrated model of the hardware.

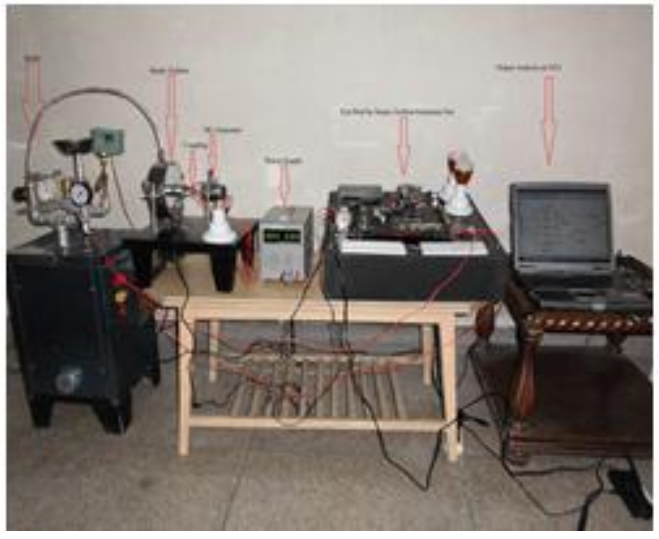

Fig. 13 Complete Integrated Picture of Hardware

\section{CONCLUSION}

Since steam turbine based power generation control is a very specialized field, therefore the practical learning regarding this matter is especially relevant.

It is very common that the academic instruction of engineers in this field lacks the practical component of in-field tests, due to difficult access to these installations. In this research work, a learning and training oriented system for the monitoring and control of steam turbine-generator set test bed has been developed and three different case studies have been executed and tested in laboratory.

The system includes two sections, section one allows for the conduction of tests on a laboratory scaled test bed composed of a steam turbine coupled with a generator. With this equipment, the effectiveness of the steam turbine-generator set regulation can be analyzed. The major parts of this system are boiler, DC motor; bang-bang controller based valve \& steam turbine-generator set.

The second phase is the development of the interactive software written in MATLAB/Simulink that gives the complete picture of parameters under consideration and the data is synced to the MATLAB/Simulink via RS-232 serial protocol, plotted, and analyzed.

The system will allow examining the relationship of key parameters such as current, voltage, power utilization, turbine rpm, steam pressure, and steam temperature of the steam turbine-generator set parallel to the load variations.

\section{REFERENCES}

[1] Jaime R. Arribas, Carlos Veganzones, \& Francisco Blázquez. (2011). Computer-Based Simulation and Scaled Laboratory Bench System for the Teaching and Training of Engineers on the Control of Doubly Fed Induction Wind Generators. Power Transactions on Power Systems, IEEE, pp. 1534-1543. http://dx.doi.org/10.1109/TPWRS.2010.2083703

[2] P. Jennings. (2009). New directions in renewable energy education. Renewable. Energy, vol. 34, no. 2, pp. 435-439. http://dx.doi.org/10.1016/j.renene.2008.05.005

[3] Y. M. Atwa, E. F. El-Saadany, M. M. A. Salama, \& R. Seethapathy. (2011). Optimal renewable resources mix for distribution system energy loss minimization. Trans. Power Syst., IEEE, vol. 25, no. 1, pp. 360-370.

[4] B. Brännbacka \& T. Vekara. (2004). A system for education of wind power at the University of Vaasa, in Proc. Nordic Workshop Power and Industrial Electronics, Trondheim, Norway. 
[5] Ashish Tewari. (2002). Modern Control Design with MATLAB \& Simulink. pp. 1-4, John Willey \& Sons, Ltd.

[6]. Mohamed .M. Ismail. (2012). Adaptation of PID Controller using AI Technique for Speed Control of Isolated Steam Turbine. Japan-Egypt Conference on Electronics, Communication \& Computers, vol., no., pp. 85-90.

http://dx.doi.org/10.1109/JEC-ECC.2012.6186962

[7]. Terry Bartet. (2011) Industrial Electronics: Circuits, Instruments, and Control Techniques. 78-93, Cengage Learning India Private, Ltd.

[8] O. A Mohammed, L. Henao, F. Rojas, \& A. A. Khan. (2008) Experimental real-time voltage and frequency controllers for a synchronous generator implemented in a laboratory power system testbed. $34^{\text {th }}$ Annual Conference on Industrial Electronics (IECON), IEEE. http://dx.doi.org/10.1109/iecon.2008.4758525

[9] D. Ramirez, S. Martinez, J. Rodriguez, C. Carrero, \& M. Blanco. (2009). Educational tool for the implementation of electric drives control system with real time data exchange. Int. J. Eng. Educ., vol. 25, no. 1, pp. 24-32. 